\title{
sciendo
}

\section{Acquaintance and Mental Files}

\author{
J. Keith Hall \\ University of Southern California \\ BIBLID [0873-626X (2013) 36; pp. 119-132]
}

DOI: $10.2478 /$ disp-2013-0012

In recent years there has been an ongoing debate about whether singular thought requires acquaintance. Although few nowadays accept Russell's view that we are only ever acquainted with sense data, many philosophers continue to maintain that in order to have a singular thought about an object, a subject must have some intimate epistemic or causal connection with it. On the other hand, those in the anti-acquaintance camp have challenged the motivations for imposing acquaintance constraints on singular thought, and have argued that there are serious difficulties confronting such views. ${ }^{1}$ In Mental Files, Recanati's answer to the anti-acquaintance theorists is to grant that there is no de facto acquaintance constraint on singular thought, but to insist that there is still a de jure one. On his view, in order to think a singular thought about an object, a subject must possess a mental file that refers to it. Moreover, in order for a subject to possess a mental file, she must be acquainted with its referent. But this does not entail that there are no acquaintanceless singular thoughts. 'Must' may be factive on some readings and merely normative on others. Recanati's interesting idea is that the acquaintance condition on mental files is an instance of the latter. If Recanati is right, then acquaintance is involved in the very concept of a mental file, and by extension, singular thought. In this paper, I will evaluate Recanati's answer to the anti-acquaintance theorists. I begin with a brief discussion of Recanati's account of mental files.

\footnotetext{
${ }^{1}$ On the acquaintance side are Bach 1987, Boer and Lycan 1986, Donnellan 1979, Evans 1982, Kaplan 1989, McDowell 1984, Recanati 1993, Reimer 2004, Salmon 1987, and Soames 2003. Jeshion 2002, 2004, (forthcoming), Manley and Haw thorne 2012, and Sainsbury 2005 reject the acquaintance constraint.

Disputatio, Vol. V, No. 36, October 2013
} 


\section{Mental files as non-descriptive modes of presentation}

Mental files are cognitive structures that bind together information that a subject takes to be about the same external object. Like Fregean senses, they serve to individuate our cognitive perspectives on objects of thought. On Recanati's view, mental files are non-descriptive modes of presentation — ways that objects are 'given to us' directly, rather than by description (34). The idea behind this metaphor is that whereas the referent of a descriptive mode of presentation is determined satisfactionally (i.e. by virtue of the referent satisfying some set of descriptive conditions), the referent of a non-descriptive mode of presentation is determined relationally. ${ }^{2}$ In particular, mental files function to store information about the objects that subjects bear acquaintance relations to, where acquaintance is construed as a relation through which a subject may receive information from an object (Recanati calls these 'epistemically rewarding' or 'ER' relations). Drawing on the standard type-token distinction, files are typed by their corresponding acquaintance relations. Each file-type $M$ is associated with an acquaintance relation $R_{M}$ such that the referent of a file-token $m$ of type $M$ is the unique object $o$ to which the subject stands in the $\mathrm{R}_{\mathrm{M}}$ relation. ${ }^{3}$ In a word, the referent of a mental file is the dominant source of, rather than the object that best satisfies, the (mis)information contained in the file.

In this way, Recanati's mental files have a non-descriptive semantics and so they are the mental analogues of referring terms. Since singular contents are contents expressed by sentences containing referring terms, as one might expect the contents of thoughts that involve mental files are also singular. But here Recanati draws on the distinction that is often made between thoughts with singular content and thoughts with singular form. Singular contents are often characterized as object-dependent in the sense that they are neces-

${ }^{2}$ Cf. Bach 1987 on the satisfactional-relational distinction.

${ }^{3}$ Recanati qualifies this view (70, note 1$)$ : the referent of a file $m$ of type $M$ tokened by a subject $S$ is the unique object $o$ such that $m$ stands in the tokenreflexive relation $\mathrm{R} *$ to $o$, where $\mathrm{R} *$ holds between a file $m$ and object $o$ if and only if $m$ serves to store information gained by $\mathrm{S}$ in virtue of $\mathrm{S}$ 's standing in the associated relation $\mathrm{R}_{\mathrm{M}}$ to $o$. Since this qualified semantics doesn't matter for the purposes of this paper, I stick with the simpler presentation. 
sarily about the object or objects that they are actually about. ${ }^{4}$ If we assume that thoughts can only be about objects that exist, this characterization implies that one's thought has a singular content only if there exists an object one's thought is about. But just as one might think that ordinary referring expressions ('Aristotle', 'Venus') and empty names ('Vulcan', 'Santa Claus') form a single semantic category of referring expressions ${ }^{5}$, some philosophers have thought that there is a single cognitive or psychological category - singular thoughts - that encompasses both thoughts with singular content and thoughts for which there exists no object that one's thought is about. To be a singular thought in this sense, a thought-episode need only purport to have a singular content; there needn't be any object that it is a representation of. ${ }^{6}$ For Recanati, the singular form or referential purport of a thought episode is accounted for by the non-descriptive semantics of the cognitive 'vehicles' that subjects deploy in such episodes. So mental files are the 'vehicles' of singular thoughts.

By drawing the distinction between singular thought 'vehicles' and singular content, Recanati splits the question of acquaintance constraints on singular thought in two: first, is acquaintance required for a subject to entertain a singular content? And second, is acquaintance required for a subject to deploy a mental file? Recanati's answers to these questions have much to be said for them. However, on my view, neither is ultimately correct. In the next section, I argue that the loophole Recanati provides in the acquaintance constraint on entertaining singular contents is insufficiently motivated and generates unsatisfactory conclusions when combined with the other theoretical commitments of his framework. Finally, in the last section I argue that there are a number of problems confronting Recanati's de jure acquaintance constraint on mental files that should make us skeptical that the primary function of files is characterizable

${ }^{4}$ Cf. Evans 1982 and McDowell 1984. For Recanati, on one way of disambiguating the term 'content', the contents of thoughts are Russellian propositions. Since Russellian singular propositions are object-dependent, Recanati endorses an object-dependent conception of singular contents.

${ }^{5}$ Cf. Sainsbury 2005.

${ }^{6}$ As Ken Taylor puts it 2009, thoughts can be 'referentially fit' without being 'referentially successful'. 
in terms of acquaintance.

\section{Acquaintance and singular content}

Although the function of Recanati's files is to store information obtained through a corresponding acquaintance relation, there can be malfunctions: files can be tokened even when there is no object that the subject uniquely stands in the relevant acquaintance relation to. Since mental files can fail to refer in this way, opening a file is not sufficient for a subject to have a thought with singular content. In order for a subject to have a thought with a singular content about an object $o$, she must posses a file that refers to it (155). Since the referent of a file is determined by its associated acquaintance relation, one would expect Recanati's view to be that actual acquaintance is a necessary condition on entertaining singular contents. However, Recanati provides a loophole for cases involving descriptively introduced names - that is, names whose referents are fixed by a definite description, used attributively. Descriptively-introduced names are problematic for the acquaintance theorist because they arguably function in language and thought just as paradigmatic proper names do, but neither introducing these names into the language nor using and understanding them seems to require that agents be acquainted with their referents. ${ }^{7}$ Since sentences containing descriptive names arguably express singular contents, by introducing such names into the language speakers and thinkers can entertain the singular contents those sentences express, and thereby come to have singular thoughts about the names' referents, whether acquainted or not.

Taking up this issue, Recanati considers what he calls the Strong Acquaintance View (159), according to which speakers that introduce such names sans acquaintance are unable to grasp any singular content about the object $o$ denoted by the reference-fixing description. The problem with this view, Recanati claims, is that when a speaker introduces a descriptive name into the language prior to her

\footnotetext{
${ }^{7}$ These claims are by no means uncontroversial (cf. Jeshion 2004, Reimer 2004). In addition to the famous examples ('Neptune', 'Jack-the-Ripper', Evans' 'Julius', and Kaplan's 'Newman1'), we should also include here Kaplanian dthat terms and deferred demonstratives and pronouns.
} 
acquaintance with $o$, it is determined in advance that $o$ is to be the referent of that file whenever the speaker eventually becomes acquainted with it. Therefore,

'assuming the subject is right in his anticipation that [the acquaintance relation] is going to come about, then what reason is there to deny that, through the singular vehicle and its (delayed) connection to [o], the subject is able to think a singular thought about [o]?'8 (162).

According to the 'semi-liberal' view he adopts, it is possible for a subject to entertain a singular content about $o$ by tokening a descriptive name, but only if (i) she expects to be acquainted with $o$ and (ii) her expectation is actually fulfilled in the future.

This is puzzling. In adopting this semi-liberal view, Recanati appears to be committed to the following theses:

File Semantics. For any mental file $m$ of type $M$ tokened by a subject $S$, there is a corresponding acquaintance relation $R_{M}$ such that the referent of $m$ is the unique object $o$ such that $S$ bears $R_{M}$ to $o$.

Singular Content. A subject $\mathrm{S}$ entertains a singular content about $o$ only if $\mathrm{S}$ has a mental file whose referent is $o$.

Loophole. If a subject $\mathrm{S}$ introduces a name ' $\mathrm{N}$ ' into the language by means of a reference-fixing description 'the D' that denotes an object $o$, and thereby tokens a corresponding mental file $m$ of type $\mathrm{M}$, and if $\mathrm{S}$ does not bear any acquaintance relation to $o$, then $\mathrm{S}$ can still entertain a singular content about $o$, but only if S correctly anticipates that the acquaintance relation $\mathrm{R}_{\mathrm{M}}$ will come about. ${ }^{9}$

As will become clear in what follows, these theses cannot be jointly maintained. However, it is not clear whether in adopting Loophole Recanati intends to abandon File Semantics or Singular Content. Neither option is without serious difficulties.

\footnotetext{
${ }^{8}$ Here 'singular thought' is understood to mean singular content.
}

${ }^{9}$ It's not at all clear what it means for a speaker to anticipate acquaintance (see Section 3). But as I read him, Recanati does not intend anticipation to be understood as itself an attitude with singular content. 
If Recanati gives up Singular Content, then Loophole would allow a speaker $\mathrm{S}$ in a Loophole case to entertain a singular content about an object $o$ with which S is unacquainted, but File Semantics would prevent $\mathrm{S}$ from mentally referring to $o$ via any file she possesses. Notice that it doesn't help here to point out that $\mathrm{S}$ will be acquainted with $o$ or that $o$ will be the referent of one of S's files should she ever become acquainted with it. What we want to know is whether $\mathrm{S}$ can mentally refer to o now, prior to acquaintance. Here Recanati can go one of two routes. On the one hand, if the only way $\mathrm{S}$ can mentally refer to $o$ is via some file, then we get the absurd conclusion that speakers can entertain singular contents about objects that they cannot mentally refer to. On the other hand, if S can mentally refer to $o$ despite having no file that refers to it, then one would want to know how this is possible. Presumably one way $S$ might mentally refer in a Loophole case is by tokening a mental analogue of the relevant descriptive name. But on Recanati's picture, to token a mental name is to token a mental file. ${ }^{10}$ This route then leads Recanati to the awkward conclusion that in tokening a mental name/ file, $\mathrm{S}$ can mentally refer to $o$ and thereby entertain a singular content about it, even though the mental name/file $\mathrm{S}$ tokens does not itself refer to $o$. This strikes me as an extremely unattractive conclusion. But to make matters worse, one wonders whether Loophole will also allow speakers to communicate the singular contents they entertain in Loophole cases. If so, how is such communication possible if not by uttering a sentence containing the relevant descriptive name? On Recanati's view, however, files serve as the senses of occurrences of proper names and determine their referents. This entails that without acquaintance, files associated with descriptive names would fail to refer, and so would the corresponding name-occurrences. It is utterly mysterious how a subject could communicate a singular content about an object if she cannot refer to it. ${ }^{11}$

Another option is for Recanati to emend File Semantics (presumably he would not want to abandon it wholesale) to read: the referent of a file $m$ with associated acquaintance relation $R_{M}$ is the

${ }^{10}$ As I understand him, a mental name is just the 'address' or 'label' of a mental file (37).

${ }^{11}$ Thanks to Fiora Salis for pushing me to clarify these two points. 
unique object $o$ such that either $\mathrm{S}$ bears $\mathrm{R}_{\mathrm{M}}$ to $o$ (now) or $\mathrm{S}$ is correct in anticipating that she will bear $\mathrm{R}_{\mathrm{M}}$ to $o$ in the future. ${ }^{12}$ If acquaintance is not actually forthcoming, the file fails to refer and the subject fails to think a thought with singular content. Setting aside the rather large problem about what it means for a subject to 'anticipate' acquaintance ${ }^{13}$, one worry for this move is how correctly anticipating future acquaintance could affect the content of one's thought. How can the content of my thought now be determined or affected by what happens in the future? Anticipating this objection, Recanati says that the ultimate source of this objection might simply be the intuitive but mistaken pull of Cartesian internalism (163).

But I don't think that's right; the force of this objection is something that even card-carrying externalists could accept. Externalists about mental content believe that two subjects can be in phenomenologically indistinguishable mental states which nevertheless differ in content. What does not follow from this is that two subjects could be in phenomenologically indistinguishable mental states which nevertheless have contents of a fundamentally different kind: one having a singular content, the other having a descriptive or general thought. ${ }^{14}$ The trouble for Recanati here is not only explaining how correctly anticipating future acquaintance could affect what kind of thought one is presently thinking, but also why one needs to (i) anticipate future acquaintance at all, and (ii) be correct in so anticipating. Recanati's stated reason for Loophole is that in initiating a file alongside a descriptively-introduced name, it is determined in advance that the referent of the file/name will be the object denoted by the reference-fixing description. But then why should it matter whether a subject will ever actually be acquainted with that object? And why should it matter whether a subject anticipates acquaintance? Even if I never become acquainted with the object denoted by the description used to introduce a descriptive name, or if I never anticipate being

${ }^{12}$ Perhaps Recanati intends to give a de jure reading of File Semantics along the same lines as his de jure reading of the acquaintance constraint on file tokening. Even so, telling us what a file must refer to does not tell us what it actually refers to. So Recanati would still owe us an account of the de facto semantics for files.

${ }^{13} \mathrm{Cf}$. Section 3 for objections to this metaphor.

${ }^{14}$ Jeshion makes this same argument in her (forthcoming). 
acquainted with it, surely it is still determined in advance that that object is to be the referent of the name/file were I ever to become so acquainted. Recanati's argument for Loophole therefore gives us no reason to suppose that subjects need to anticipate forthcoming acquaintance, nor that they need to be correct in so anticipating. But if Recanati were to give up these two constraints in Loophole, then any act of descriptive reference-fixing would allow subjects to entertain singular contents without acquaintance. Although that conclusion would be welcome to me, this is precisely the sort of liberal view Recanati wishes to avoid. For this reason, I do not think that Recanati's semi-liberal position here is sustainable. If Recanati is loathe to give up all acquaintance constraints on singular content, he'd do better to give up Loophole.

\section{De jure acquaintance}

Serious difficulties also confront Recanati's acquaintance constraint on singular thought vehicles, i.e., mental files. Since files don't always refer, there is no de facto acquaintance constraint on tokening files. However, there is still a de jure acquaintance constraint. Presumably this means that one should open or token a file only if its function is or will be fulfilled - i.e. only if one does or will bear the relevant acquaintance relation to some unique object. ${ }^{15}$ In this way, Recanati stakes out middle ground between the acquaintance and anti-acquaintance camps. With the anti-acquaintance theorists, he grants that there is no de facto acquaintance constraint on singular thought (qua singular vehicles). With the acquaintance theorists, he maintains that singular thought requires acquaintance, but only if understood as a normative requirement.

There are three main problems with this position. The first concerns conclusions Recanati draws from the de jure acquaintance constraint. Because files function to store information that comes through a relevant acquaintance relation, Recanati claims that in tokening a file, subjects presuppose that its function is or will be fulfilled - that there is a unique object to which they bear the relevant acquaintance relation (61). Taken literally, this strikes me as

${ }^{15}$ Cf. Recanati (2012: 63). 
deeply implausible. 'Acquaintance' is a philosophical term of art; it is absurd to suppose that it is something that subjects think about, let alone anticipate or presuppose. Similarly, whatever mental file initiation is, it is not something that is transparently within subjects' cognitive power to perform. Recanati owes us an account of how to understand these metaphors in a way that does not attribute to subjects some implausible transparent access to their own cognitive architecture.

Unfortunately, Recanati often talks about anticipating acquaintance on the model of anticipating meeting someone. For example, he claims that in certain exceptional cases, thinkers token files without presupposing that the de jure acquaintance constraint will be met. An adopted child might initiate a mental file for his biological mother, knowing perfectly well that he will never be acquainted with her. Or I can initiate a file for the average American male, give him a name, and predicate various things of him, despite the fact that I know that there is no such person with whom I can be acquainted (168). By presenting these and other cases as examples where subjects do not presuppose that there is a unique object to which they (will) bear the relevant acquaintance relation, Recanati invites us to understand his notions of presupposed or anticipated acquaintance on the model of anticipating meeting someone. But it is difficult to see how these notions so understood could be extended to other objects of singular thought. For example, if as many philosophers believe we can have singular thoughts about abstract objects, what would it mean to anticipate or presuppose acquaintance with such objects?

A related second difficulty for de jure acquaintance concerns whether Recanati's notion of acquaintance as epistemically rewarding (ER) relations is too restrictive. Recanati characterizes ER relations as causal chains that permit the flow of information. ${ }^{16}$ But it is not at all clear that we can only have singular thoughts about objects that causally impinge on us or the files we token. In their recent

16 Recanati cites Lewis (1999: 380-1): 'There are relations that someone bears to me when I get a letter from him, or I watch the swerving of a car he is driving, or I read his biography, or I hear him mentioned by name, or I investigate the clues he has left at the scene of his crime. In each case there are causal chains from him to me of a sort which would permit a flow of information...I call such relations as these relations of acquaintance'. 
book (2012: Chapter 1), Manley and Hawthorne provide a battery of cases that create problems for the causal acquaintance theorist. To mention just a few, on a Kaplanian account of indexicals, a speaker who utters the word 'tomorrow' in a context refers to a time in the speaker's future, and so cannot bear an ER relation to it on any standard conceptions of causation. But it does not seem that speakers have any problem in mentally referring to future times, or other future existents. Or suppose a mechanic gestures at a car, saying 'Let me see that engine' (we are to imagine that the engine is hidden from view). There seems to be no barrier to the mechanic's ability to refer in thought and talk to the relevant engine, although there may be no relevant causal relation that he bears to it. Or suppose there is a linguistic convention that assigns each newborn a unique numeral as its name which is the output of some algorithm taking as its input the newborn's time and place of birth. Presumably a speaker can refer to a newborn via its assigned numeral, yet there needn't be any causal connection between the speaker's use of the numeral and the baby it names.

Here Recanati might respond that these examples involve files that have derived functions. Anticipating cases like those mentioned above, Recanati accepts that there may be files which do not require acquaintance in accordance with the de jure acquaintance constraint (168). But rather than taking such cases as counterexamples to his view, Recanati instead treats them as exceptions that prove the rule. The primary function of mental files is still characterizable in terms of ER relations; these problem cases involve files that have 'derived' functions whose fulfillment does not require acquaintance. These derived functions are parasitic on files' acquaintance-based function, and there is presumably some evolutionary story that would explain how our ability to token files with derived functions evolved from more basic abilities involving acquaintance-based files (like the ability to recognize, track, and store information about objects moving across one's visual field).

This leads us to a final difficulty for de jure acquaintance: what are the motivations for thinking that the primary function of files has anything to do with acquaintance in the first place? This is one of the central claims of Recanati's book, but as far as I can tell he provides no arguments for it other than by demonstrating how it can 
solve certain problems in the philosophy of language and mind. This methodological approach to mental files is deeply problematic. In theorizing about cognitive architecture, we are making philosophical claims, but ones that can have real empirical consequences. One such consequence concerns the psycho-functional and evolutionary relationship between philosophers' files and the cognitive structures studied by cognitive psychologists. There is a phenomenon widely studied in cognitive psychology called chunking whereby individuals performing memory tasks have been found to group information together in discrete chunks in order to aid free recall of the information. ${ }^{17}$ Chunks are superficially similar to philosophers' files, but since the information in them are not necessarily grouped together according to any semantic relationships, chunks do not have an acquaintance-based function. As a methodological point, it would be inappropriate to divorce armchair speculation about the function of mental files from empirical research, on pain of prejudging the functional and evolutionary relationship between philosophers' files and the cognitive structures posited by psychologists.

From my perspective, instances of mental files (and other superficially similar structures like chunks) whose function is ostensibly not characterizable in terms of acquaintance are neither exotic nor rare: on the contrary, they pervade our cognitive lives. ${ }^{18}$ At the very least, the proliferation of such problem-cases should make us question the motivation for taking the acquaintance-based function of files to be primary. According to an opposing paradigm, the primary function of files is simply to group information together in cognition. A special case of this occurs when that information is taken to concern the same external object, but in general the information stored in files needn't even be grouped together by subject matter. If Recanati is to maintain that the acquaintance-based function of his mental files is somehow primary, he needs to offer more by way of argument for that claim, especially if he thinks it has certain empirical con-

${ }^{17}$ Cf. George Miller's 1956 classic paper 'The Magical Number Seven, Plus or Minus Two'.

${ }^{18}$ Recanati's treatment of files with 'derived' functions is not unlike how descriptive names get treated in the philosophy of language: as semantic oddities. Cf. Jeshion 2004, who argues against this view. 
sequences for the evolutionary relationship between acquaintancebased files and files with derived functions. ${ }^{19}$

Another reason to be skeptical of the claim that the primary function of files has to do with acquaintance is that this claim leads to false predictions even in Recanati's favored cases involving acquaintancebased files. As I understand Recanati, since files' primary function is to store information obtained through a corresponding ER relation, all information stored in a given file comes through the file's characteristic ER relation. If that were right, however, one would expect that when a file is tokened without acquaintance, the subject will not be able to store any information in the file and so the file will be empty. This is implausible. Even if Leverrier was never to become acquainted with Neptune after having introduced the name into the language, that surely would not prevent him from being able to track and store information about Neptune in his NePTUNE file. But since Leverrier bears no acquaintance relation to Neptune, there is no epistemic channel through which information concerning Neptune can be received. ${ }^{20}$ So either Leverrier is unable to retain any information that he takes to be about Neptune or that information fails to be stored in his NePtune file. This can't be right.

As a result, it is not at all obvious that the empirical phenomena that Recanati's files are posited to model and explain (such as our ability to track, store, and make inferences with information that we take to be about the same external object) do not also frequently occur with thoughts that are not about objects known by acquaintance. Again, this should make us skeptical that the primary function of mental files is to store information obtained through acquaintance relations, and that the cognitive phenomena really warrant taking

${ }^{19}$ I should also like to note in passing that even if the acquaintance-based function of files is somehow evolutionarily basic, I see no compelling reason to think that the (primary) functions of files should not have evolved from their original acquaintance-based function.

${ }^{20}$ Some might deny that Leverrier lacks acquaintance with Neptune. If so, pick your favorite case. To borrow one from Manley and Hawthorne 2012, Mendeleev correctly anticipated in 1870 the existence of an element he called 'ekaaluminum' (now known as Gallium). At the time, no known samples had been discovered, yet it seems implausible to suppose that he could not have stored information in his Eка-Aluminum mental file. 
mental files to be non-descriptive modes of presentation - the mental analogues of referring expressions. Indeed, why would it be a mistake to think that there can be mental files which serve as the vehicles of paradigmatically descriptive thoughts? Or which are the mental analogues of singular terms more generally, rather than just referring terms? Shedding Recanati's acquaintance-based semantics for files would, I think, open more doors, allowing us to explore the possibility that files have a much larger role to play in our cognitive lives. ${ }^{21}$

J. Keith Hall

Mudd Hall of Philosophy (MHP)

University of Southern California 3709 Trousdale Parkway

Los Angeles, California 90089-0451

United States

johnkhal@usc.edu

\section{References}

Bach, Kent. 1987. Thought and Reference. Oxford: Clarendon Press.

Boer, Steven E. and Lycan, William G. 1986. Knowing Who. Cambridge: MIT Press.

Donnellan, Keith. 1979. The contingent a priori and rigid designators. Midwest Studies in Philosophy, 2: 12-27.

Evans, Gareth. 1982. The Varieties of Reference. Oxford: Clarendon Press.

Kaplan, David. 1989. Afterthoughts. In Themes from Kaplan, ed. by Joseph Almog, Howard K. Wettstein, and John Perry. New York: Oxford University Press.

Jeshion, Robin. 2002. Acquaintanceless de re belief. In Meaning and Truth: Investigation in Philosophical Semantics, ed. by Campbell, O'Rourke, and Shier. New York: Seven Bridges Press.

Jeshion, Robin. 2004. Descriptive descriptive names. In Descriptions and Beyond, ed. by Marga Reimer and Anne Bezuidenhout, 591-612. Oxford: Oxford University Press.

Jeshion, Robin. (Forthcoming.) Two Dogmas of Russellianism. To appear in Empty Representations: Reference and Non-existence, ed. by Manuel Garcia-Carpintero and Genoveva Marti. Oxford: Oxford University Press.

Lewis, David K. 1999. Papers in Metaphysics and Epistemology. Cambridge: Cambridge University Press.

Manley, David and Hawthorne, John. 2012. The Reference Book. Oxford: Oxford University Press.

Miller, George A. 1956. The magic number seven, plus or minus two: Some limits on our capacity for processing information. Psychological Review, 62 (2): $81-97$.

${ }^{21}$ I am grateful to Robin Jeshion and Fiora Salis, whose comments and suggestions were immensely helpful in earlier drafts of this paper. 
McDowell, John. 1984. De re senses. Philosophical Quarterly, 34: 283-94.

Recanati, François. 1993. Direct Reference: From Language to Thought. Oxford: Basil Blackwell.

Recanati, François. 2013. Mental Files. Oxford: Oxford University Press.

Reimer, Marga. 2004. Descriptive names. In Descriptions and Beyond, ed. by Marga Reimer and Anne Bezuidenhout. Oxford: Oxford University Press.

Sainsbury, Mark. 2005. Reference Without Referents. Oxford: Oxford University Press.

Salmon, Nathan. 1987. How to measure the standard metre. Proceedings of the Aristotelian Society, 88: 193-217.

Soames, Scott. 2003. Philosophical Analysis in the Twentieth Century, vol. 2. Princeton: Princeton University Press.

Taylor, Kenneth. 2009. On singularity. In New Essays on Singular Thought, ed. by Robin Jeshion. Oxford: Oxford University Press. 